\title{
Testes ABC: proposta de governo de uma população problemática
}

\section{Ana Laura Godinho Lima}

Neste texto, examina-se a criação do objeto "maturidade para aprender a ler e a escrever" e o estabelecimento de suas relações com outros objetos: idade cronológica, idade mental, reprovação escolar, subnutrição e auto-estima, entre outros, tais como configurados por Lourenço Filho (1974) no livro Testes $A B C$ para verificação da maturidade necessária à aprendizagem da leitura e da escrital. O objetivo é verificar como essas categorias foram mobilizadas na formulação dos Testes $A B C$, uma estratégia de governo pensada para resolver o problema específico de uma população de alunos e avaliar o desempenho dos professores dessas crianças. Além disso, o mesmo recurso foi considerado recomendável para o diagnóstico inicial da "criança-problema" no espaço escolar.

A análise baseia-se nos escritos de Foucault (1979/ 1996, 1988/1999) sobre a governamentalidade e a biopolítica. Nessa perspectiva, o governo é considerado como sendo a "conduta da conduta", ou como "uma correta disposição das coisas de que se assume o encargo para conduzi-las a um fim conveniente" (Guillaume de La Perrière apud Foucault, 1996; 282). Essa maneira de entender o governo tem diversas implicações. Em primeiro lugar, significa destituir o Estado de um papel central no exercício do poder. Em segundo lugar, embora tenham como princípio geral dirigir o comportamento de outros, os objetivos do governo não são sempre os mesmos. Da mesma maneira como há múltiplos governos, há múltiplos objetivos. Em terceiro lugar, se há finalidades específicas para dispor as coisas e as pessoas de maneira conveniente, é preciso adquirir conhecimentos sobre elas. $O$ exercício do poder requer, portanto, formas de saber. Rose (1999) entende que o conceito de governamentalidade pode delinear um campo onde localizar todos os estudos sobre as operações modernas de saber/poder, dentre os quais o primeiro volume da obra História da Sexualidade (Foucault, 1988/1999) constitui um caso exemplar. Nesse caso, trata-se das tecnologias de bio- política direcionadas para uma unidade específica do governo, a "população".

O poder sobre a vida concretizou-se ao longo de dois pólos: em primeiro lugar, o investimento sobre o corpo dos indivíduos, a partir da difusão das técnicas disciplinares por todo o corpo social, processo iniciado no século XVII. Mediante o emprego das disciplinas, tratou-se simultaneamente de ampliar as forças e a sujeição do homem-máquina, mediante um controle minucioso exercido sobre cada parte do seu corpo (Foucault, 1988/1999). Em segundo lugar, a partir de meados do século XVIII, o governo dedicou-se a conhecer e a intervir nos processos biológicos da população: as taxas de natalidade e mortalidade, a saúde e as doenças, a duração da vida humana e os fatores que os influenciam passaram a ser estudados e administrados pela bio-política.

Pode-se considerar que os testes $A B C$ funcionaram como um recurso de bio-política na medida em que seu emprego nas escolas primárias paulistanas no início da década de 1930 buscou produzir conhecimentos sobre a aprendizagem dos alunos e o trabalho dos professores para favorecer a organização do ensino e simultaneamente atender ao interesse da administração escolar de tornar mais eficiente o sistema e reduzir os gastos com a reprovação escolar. Conforme já se explicitou, a bio-política consiste numa forma de poder que se baseia em conhecimentos sobre a vida dos indivíduos e as características das populações com o objetivo de preservar e promover as condições de vida desses mesmos indivíduos, na medida em que isso seja considerado importante para o próprio Estado. Assim como os outros testes produzidos pela psicologia experimental nas primeiras décadas do século $X X$, os testes $A B C$ também podem ser considerados como um recurso da biopolítica porque produziram conhecimento sobre um aspecto da vida dos alunos - sua maturidade para o aprendizado da leitura e da escrita. E foi esse conhe-

'Esta análise baseia-se na $12^{\mathrm{a}}$. ed., São Paulo, Melhoramentos, 1974. A primeira edição desta obra é de 1933. 
cimento que permitiu intervir na população, organizála em grupos mais homogêneos, legíveis e administráveis. Efetuava-se a classificação com o objetivo de melhorar as condições de vida dos alunos e dos professores na escola. Tudo isso interessava à administração do ensino na medida em que resolvia um problema de governo, a necessidade de reduzir as taxas de reprovação escolar. A seguir, procura-se examinar mais detidamente as especificidades desse problema e da solução para ele proposta.

\section{Exposição sobre o problema e a maneira de enfrentá-lo.}

Uma grave dificuldade encontrada nas escolas públicas brasileiras desde o início do século $X X$, era $\circ$ elevado índice de reprovações na primeira série do ensino primário. De acordo com os dados apresentados pelo educador Lourenço Filho $(1974,104)$ para a cidade de São Paulo, nos anos de 1928 a 1930, a média das promoções no primeiro ano variaram de $62,02 \%$ em 1928 a $64,60 \%$ em 1930. A primeira série constituía um motivo de grande preocupação para a administração escolar e representava o fracasso da escola pública em cumprir a sua função primordial de ensinar o povo a ler e a escrever. Nesta época, a grande maioria das crianças não frequentava $\circ$ jardim da infância e a primeira série representava a sua experiência escolar inicial. Desse modo, os alunos da primeira série compunham uma população heterogênea, formada por crianças desconhecidas, que ainda não haviam sido "normalizadas" pelo governo escolar. E o primeiro ano de trabalho resultava em quase $40 \%$ de reprovações.

Para solucionar esse problema, o educador Lourenço Filho criou os Testes $A B C$, que ofereciam a possibilidade de organizar essa população desordenada que chegava às escolas todos os anos. Tratava-se de oito testes que mediam a "maturidade" das crianças para o aprendizado da leitura e da escrita e cujos resultados distribuíam-se na forma de uma curva normal, a partir da qual era possível dividir a população em três grupos "homogêneos" de crianças: fortes, médias e fracas. Esses testes eram apresentados, portanto, como a possibilidade de estabelecer uma classificação inicial dos alunos ingressantes na escola primária, que ofereceria aos professores uma base mais segura para o início do trabalho. Os resultados dos alunos nos testes permitiam prever ainda o tempo necessário à aprendizagem da leitura e da escrita, em condições "normais": o grupo forte seria capaz de aprender a ler e a escrever sem maiores dificuldades em apenas um semestre, o grupo médio aprenderia normalmente no prazo de um ano letivo e o grupo fraco não conseguiria aprender no prazo estabelecido a não ser em condições especiais, com atendimento individualizado e em classes com um número reduzido de alunos.

O exame era individual, para que fosse possível observar e anotar o comportamento e a atitude geral da criança em cada teste, o que serviria como base para o estudo individual dos alunos. As oito provas verificavam, de acordo com o autor, os seguintes índices de maturidade, considerados necessários ao aprendizado da leitura e da escrita: I. coordenação visualmotora; 2. resistência à inversão na cópia de figuras; 3. memorização visual; 4. coordenação auditivo motora; 5. capacidade de prolação; 6. resistência à ecolalia; 7 . memorização auditiva; 8. índice de fatigabilidade; 9. índice de atenção dirigida; 10. vocabulário e compreensão geral ( Lourenço Filho, 1974, p. 57).

Os testes $A B C$ eram apresentados como um recurso simples, rápido, eficiente e econômico. Em apenas oito minutos, aproximadamente, era possível identificar o grau de maturidade de uma criança para o aprendizado da leitura e da escrita e prever o tempo e os recursos necessários para ensiná-la a ler e a escrever. "Qualquer pessoa, de satisfatório cultivo", poderia aplicar o exame, bastava que tivesse uma atitude adequada, observando o seguinte:

"O que é preciso é ler atentamente este Guia de Exame e dispor-se ao trabalho com boa vontade, compreendendo o alcance das provas. $O$ Examinador deve mostrar-se afável, acolhedor, mas sem excessos de afagos ou pieguices, que também perturbam a criança. Iniciado o exame, deve cingir-se rigorosamente às fórmulas adiante indicadas. No caso de a criança não ter entendido, repetirá a fórmula, nada mais. Qualquer que seja a reação do aluno, encorajá-lo, dizendo: 'Muito bem!' Não deve 
falar muito alto nem muito baixo, mas em tom sempre igual, clara e pausadamente. Deve evitar qualquer gesto de impaciência ou expressão fisionômica que denuncie a má impressão que, porventura, possa ir tendo da criança submetida ao exame. A regra fundamental é a de que a criança esteja à vontade, calma, interessada no trabalho, e confiante no examinador." (Lourenço Filho, 1974, p. 125).

Por um lado, a passagem transcrita anteriormente demonstra que o autor levava em consideração o risco da atitude do examinador influenciar a criança durante a execução dos testes, provocando uma distorção em seus resultados. Por outro lado, acreditava na possibilidade de neutralizar essa interferência mediante a definição e a observância de regras claras durante a aplicação do exame. Entendia que assim seria possível ter acesso ao "verdadeiro" grau de maturidade das crianças e organizar o ensino da leitura e da escrita sobre bases mais seguras.

\section{Repercussão dos testes $A B C$ em sua época}

$\mathrm{Na} 12^{\mathrm{a}}$. edição da obra, datada de 1974 , o autor apresenta uma série de informações sobre o emprego dos testes ABC no Brasil. Em 1931, antes mesmo da primeira edição da obra, quando ocupava o cargo de Diretor Geral do Ensino no estado de São Paulo, Lourenço Filho fez com que 15.605 crianças analfabetas matriculadas nos 54 grupos escolares da capital passassem pelo teste. No ano seguinte, 2.410 crianças do Distrito Federal realizaram as provas. Na mesma época, Helena Antipoff experimentava a aplicação dos testes nas classes anexas à Escola de Aperfeiçoamento Pedagógico, em Belo Horizonte. Os testes também haviam sido aplicados nesse período em uma instituição para crianças anormais em São Paulo (Instituto Médico Pedagógico, dirigido pelo Dr. Joaquim Penino) e no Instituto Sete de Setembro, no Rio de Janeiro, pelo Prof. Murilo Braga (Lourenço Filho, 1974). O autor oferecia ainda dados sobre a tradução do livro e sua utilização em outros países da América Latina, na França e nos Estados Unidos. Na Ar- gentina, em 1967 o Conselho Nacional de Educação deliberara que, dentre as crianças menores de sete anos, aquelas que fossem bem sucedidas nos testes $A B C$ poderiam matricular-se na primeira série das escolas públicas.

Na revista Educaçãó2, a partir de 1931 e até 1945, diversos textos fazem referência aos testes $A B C$. $O$ primeiro deles é da autoria do próprio Lourenço FiIho, e apresenta um volume especial da revista, todo dedicado aos testes. Nesse artigo, Lourenço Filho já dava notícia da aplicação dos testes em mais de vinte mil crianças, experiência que resultara na organização de 468 "classes diferenciais" (Lourenço Filho, 1931). Dois anos depois, Onofre Penteado Junior (1933) escreve para a Revista de Educação o texto "Os Testes A. B. C. como meio de seleção de classes", defendendo a adoção dos testes e lamentando o desinteresse da administração do ensino por sua aplicação depois da saída de Lourenço Filho da Diretoria do Ensino (Penteado Junior, 1933). No mesmo ano, publica-se na revista outro artigo do autor dos testes, que constitui uma apresentação do problema que os testes viriam resolver, "O problema da Maturidade para a Leitura e a Escrita" (Lourenço Filho, 1933). Nos anos seguintes, aparecem outros artigos fazendo o elogio do processo de seleção dos alunos da primeira série com base nos resultados dos testes $A B C$, dois deles redigidos por diretores de grupos escolares. Em 1939, a revista traz um texto da Comissão de Instituições Auxiliares da Escola com explicações sobre os testes e orientações minuciosas sobre a maneira correta de aplicá-los. Campos (1944), dá notícia da aplicação dos testes $A B C$ nos alunos da primeira série e da realização de exercícios corretivos com as crianças para sanar os problemas identificados pelos testes. Em 1945, Armando dos Santos, delegado regional do ensino, relata o processo de aplicação dos testes $A B C$ para a seleção dos alunos da primeira série em cinco escolas de Rio Claro. $O$ autor informava ainda os resultados de um inquérito realizado junto aos diretores das escolas sobre a aplicação dos testes e o trabalho com as classes

\footnotetext{
${ }^{2}$ O título dessa revista foi alterado diversas vezes. Do início, em 1927 a setembro de 1930, o periódico chamou-se Educação; de outubro de 1930 a julho de 1931, Escola Nova; de agosto de 1931 a dezembro de 1932, Educação novamente e de 1933 a I96I, Revista de Educação.
} 
selecionadas. Finalmente, no ano de 1951 publica-se na Revista de Educação "A seleção de alunos e o rendimento escolar" (Vollet, 195I), fazendo a defesa da aplicação dos testes $A B C$ para a formação de classes seletivas.

Conforme esses dados demonstram, os testes $A B C$ tiveram uma influência significativa nos discursos dos educadores da época e foram de fato empregados em diversos contextos para selecionar as crianças da primeira série, embora não tenham chegado nem perto de atingir o grau de generalização nas escolas públicas brasileiras que o seu autor desejaria. Elaborado numa época em que os testes eram considerados como indispensáveis à adequada organização do ensino, num tempo em que não apenas os testes de inteligência povoavam os textos pedagógicos, mas também se reivindicava a substituição das avaliações escolares tradicionais por provas de tipo teste, seria possível esperar, talvez, que os testes $A B C$ tivessem um impacto maior na organização geral das escolas públicas. Quando se lê no livro que a seleção das crianças nos grupos escolares da cidade de São Paulo em 193I teve como resultado um aumento expressivo na taxa de aprovações dos alunos da primeira série naquele ano (passou-se de $64,60 \%$ em 1930 para $81,97 \%$ em 1931), tudo leva a crer que o procedimento tenha sido continuado nos anos seguintes. No entanto, não foi o que ocorreu. Apenas durante o período em que o especialista em psicologia educacional coincidiu com o administrador, na figura de Lourenço Filho, a tecnologia de governo por ele concebida pôde ter eficácia. Já em 1932, com a mudança do Diretor do Ensino, abandonaram-se os testes e a seleção. Este evento mostra que mesmo as tecnologias de governo mais promissoras têm as suas fragilidades, enfrentam oposições e dependem de uma série de condições para que possam se difundir, num processo frequentemente marcado por falhas, descontinuidades e interrupções. Ainda assim, é lícito considerar que a formulação dos testes $A B C$ teve um impacto significativo nos discursos e nas práticas educacionais nos anos seguintes à sua publicação. Vale a pena, portanto, compreender melhor o alcance desses testes, como tecnologia de governo, mediante um exame mais detalhado da proposta do autor.

\section{Vantagens do emprego dos testes $A B C$, segundo seu criador}

De acordo com Lourenço Filho (1974), a seleção dos alunos com base no critério da maturidade permitiria resolver, entre outros, três problemas graves do ensino da leitura e da escrita nas classes iniciais: em primeiro lugar, permitiria identificar aquelas crianças que, por ainda não terem atingido o nível de maturidade necessário para a aprendizagem da leitura e da escrita, não deveriam ser introduzidas diretamente no ensino formal, mas requeriam primeiro um trabalho pré-escolar a ser desenvolvido nos primeiros meses da primeira série. Os testes permitiam ainda um diagnóstico inicial de outras dificuldades como retardamento mental, problemas de saúde - visão e audição - e desajustamentos emocionais. Nesses casos, seria preciso proceder a exames complementares, que ofereceriam dados mais consistentes sobre as medidas terapêuticas recomendadas para cada caso. $O$ autor entendia ainda que as escolas não deveriam aceitar a matrícula de crianças com baixo QI, as quais deveriam ser encaminhadas a instituições ou classes especiais. Por outro lado, considerava que outros problemas talvez pudessem ser resolvidos na própria escola, se necessário com a ajuda do médico, ou da família.

Em segundo lugar, mediante a seleção efetuada com base nos Testes $A B C$, era possível adequar o ensino às condições de aprendizagem de cada grupo - forte, médio e fraco - tornando o trabalho mais eficiente, na medida em que todas as crianças caminhariam juntas. Para as crianças fracas seria preciso propor exercícios estimulantes ou corretivos, que favorecessem a superação de suas deficiências. Por outro lado, as crianças mais aptas do grupo forte poderiam, eventualmente, ser aprovadas para a segunda série ao final do primeiro semestre, de maneira que sua escolaridade fosse acelerada de acordo com seu potencial. Este ajustamento do ensino às características do grupo oferecia ainda o benefício de contribuir para a manutenção da disciplina escolar, uma vez que nenhum aluno se sentiria desinteressado ao defrontar-se com dificuldades além de suas forças e, por outro lado, ninguém se sentiria desmotivado pela falta de desafios. Na opinião de Lourenço Filho (1974), a 
homogeneização dos grupos era fundamental para prevenir a frustração, que levava ao sentimento de inferioridade entre as crianças mais imaturas, quando colocadas entre crianças mais capazes. Esse era um ponto fundamental na defesa da seleção das classes, pois os sentimentos de segurança, auto-estima e confiança nos professores eram tidos como imprescindíveis para o sucesso da aprendizagem. Além disso, as classes selecionadas, garantindo mais eficiência ao ensino da leitura e da escrita, melhorariam o rendimento do ensino nas séries iniciais, o que significaria a diminuição no número de reprovações anuais e, consequentemente, redundaria em economia para os cofres públicos, que seriam aliviados do pesado e inútil encargo das reprovações. Dessa maneira, condições psicológicas dos alunos tais como maturidade, motivação e auto-estima, são consideradas simultaneamente questões educacionais e políticas. Os testes aparecem como uma tecnologia de governo que permite equacionar ambos os problemas: o de promover condições mais adequadas ao ensino e o de evitar o desperdício de recursos públicos causado pelo excesso de reprovações na primeira série.

Em terceiro lugar, as classes homogêneas permitiriam uma avaliação mais justa do trabalho docente, visto que, pelo sistema regular, sem que se conhecesse o número de crianças maduras e imaturas em cada classe, os professores que tinham a má sorte de receber maior número de alunos imaturos eram julgados pelos mesmos critérios daqueles que recebiam alunos mais maduros, o que constituía uma injustiça porque, claramente, o desempenho dessas classes não poderia ser igual. $O$ estabelecimento das classes homogêneas permitiria adequar as expectativas de rendimento de cada turma ao seu nível de maturidade e assim os integrantes do magistério poderiam ser avaliados de maneira mais precisa e mais justa. As classes selecionadas possibilitavam identificar ainda diferenças de rendimento entre professores com classes de níveis equivalentes de maturidade, o que tornaria evidentes as falhas daqueles cujas classes apresentassem rendimento inferior ao esperado. Os testes $A B C$ funcionavam, portanto, como auxílio precioso não apenas no governo dos alunos, mas também dos professores.
Para justificar a "maturidade" como critério para a seleção das classes, em vez da idade cronológica ou mesmo da idade mental, que poderia ser aferida pelo teste de QI criado por Binet e Simon, Lourenço Filho $(1974,17)$ explicava que a "maturidade" era o fator que apresentava o mais elevado índice de correlação com o desempenho das crianças no aprendizado inicial da leitura e da escrita. Ele rejeitava a organização do ensino realizada com base apenas na idade cronológica da criança e nas características do "aluno médio", que considerava como um "tipo monstruoso e contrário à natureza". Para o autor, não bastava saber que a média das crianças era capaz de aprender a ler e a escrever a partir dos sete anos de idade, era preciso individualizar a questão. A idade mental também não constituía um índice seguro, porque o aprendizado inicial da leitura e da escrita dependia de capacidades que os testes de idade mental não avaliavam: além de um domínio inicial da linguagem, as crianças deveriam apresentar também uma certa "maturidade" que, conforme o autor, expressava-se "por coordenação visual-motora e auditivo-motora da palavra, de atenção e fatigabilidade" (28).

A esse respeito, interessa considerar as "condições perturbadoras do equilíbrio orgânico", entendidas como fatores que podiam estar associados à imaturidade das crianças. Em primeiro lugar, fazia-se referências às "condições gerais de saúde", com ênfase no problema da subnutrição. Nessa parte, o autor citava um estudo que concluíra, mediante o exame médico de uma classe de imaturos, que $72,5 \%$ das crianças eram subnutridas (Lourenço Filho, 1974, I45146). O item mais significativo, no entanto, era "condições de ajustamento em geral" ou "dificuldades de adaptação social", onde se verifica que a maturação, apesar de ser entendida como um processo interno do organismo, não era de fato independente das influências externas, na medida em que as crianças que viviam em meios familiares desajustados, sendo "rudemente castigadas" pelos pais podiam apresentar "deficiências de maturidade" (Lourenço Filho, 1974). Mas não se tratava apenas dos castigos. Os problemas gerais de ajustamento muitas vezes eram devidos à origem sócio-econômica das crianças, como indica a seguinte passagem do texto: "Ainda hoje nu- 
merosas crianças, provindas de famílias em condições econômico-sociais menos favoráveis, vão para a escola intimidadas. Outras jamais tiveram ocasião de pegar num lápis e de exercitar-se com ele; seu vocabulário pode ser restrito e inadequado" (Lourenço Filho, 1974, 148). Apesar de considerar essas questões sociais como tendo influência sobre o "equilíbrio orgânico" da criança, em outra parte do livro, na qual se ofereciam os resultados da aplicação dos testes em 22.115 alunos das escolas do Distrito Federal no ano de 1934, o autor afirmava que a origem social das crianças não parecia ter efeito sobre o seu desempenho nos testes (79).

Identificado o problema, em seguida oferecia-se a seguinte recomendação: "Como adiante se verá, certo número de exercícios de adaptação poderão ter uma influência muito favorável nessa hipótese" (Lourenço Filho, 1974, p.I48). O autor afirmava que esses exercícios não eliminariam as "deficiências de maturidade", mas seriam úteis na medida em que levariam a criança "a melhor coordenar os seus próprios recursos, iniciando uma capacitação de tipo préescolar, que não tiveram no lar" (idem). Esse trecho é importante porque permite verificar como o problema da maturidade, considerado inicialmente como sendo um processo orgânico e interno era a seguir compreendido como sendo estreitamente relacionado ao problema social da adaptação, que poderia ser corrigido a partir de um treinamento, ou seja, da realização de exercícios que compensariam na criança uma falta devida, em parte, à sua origem social e econômica. $\mathrm{O}$ autor ainda conclui esta parte afirmando que "A regra de ouro para todos esses casos é a atenção carinhosa e compreensiva do mestre", trazendo novamente para a discussão o fator psicológico (Lourenço Filho, 1974, p. I48). Explicava que para aprender a criança precisava sentir-se segura e confiante em sua própria capacidade. $O$ fator psicológico era ainda reforçado no último item, "casos típicos de psicologia clínica", no qual se inseriam os "alunos-problema", "a exigirem tratamento psicológico especializado" e eventualmente também as crianças canhotas, não por serem canhotas, mas nos casos frequentes de não serem compreendidas pela família e pela escola (idem). Assim, a questão da imaturidade, que em princípio parecia apenas uma questão do desenvolvimento biológico da criança, no decorrer do livro tornava-se também uma questão da medicina, da assistência social, da educação e da psicologia.

De acordo com Foucault (1979//996), o governo das populações não se limita a atuar superficial e globalmente, mas se exerce também nos detalhes e profundamente. Como uma tecnologia criada para governar populações de alunos, os testes $A B C$ não se limitavam a realizar uma ordenação geral da população em três grupos: fortes, médios e fracos, mas permitia ainda traçar perfis de cada classe e até perfis individuais de cada aluno, pelos quais os professores orientariam o trabalho. Pelo perfil da classe, era possível identificar as deficiências do grupo e criar exercícios corretivos e estimulantes que beneficiariam a maioria dos alunos e, com base no perfil de cada um, podia-se fazer as correções ou oferecer estímulos necessários à superação das dificuldades individuais.

\section{A aplicação dos Testes ABC nas "crianças- problema"}

Embora não tivessem sido desenvolvidos para esta finalidade, os testes $A B C$ permitiam, de acordo com seu criador, identificar indícios de problemas de ajustamento nas crianças. Isso era possível porque o exame era aplicado individualmente e, dessa maneira, permitia observar a atitude geral da criança. Os examinadores eram orientados a tomar notas de todas as reações dos alunos durante a prova, uma vez que suas anotações poderiam oferecer pistas iniciais sobre a presença de problemas. $O$ diagnóstico definitivo, contudo, ficaria na dependência de estudos complementares posteriores, como a aplicação de outros testes ou a elaboração de um estudo de caso minucioso. Para a observação inicial da criança durante a realização dos testes, Lourenço Filho oferecia um esquema, contendo descrições de comportamentos possíveis nas provas individuais e suas prováveis interpretações. A definição oferecida por Lourenço FiIho para "criança-problema" era:

"a denominação crianças-problema foi criada para designar aquelas cujo comportamento seja menos comum que o das outras, por ser emocio- 
nalmente mais complexo. De modo geral, representam crianças com dificuldades de ajustamento no meio familiar ou mesmo na escola; retratam conflito íntimo, que podemos reconhecer tentando interpretar as suas reações emocionais." (Lourenço Filho, 1974, I70).

A definição que indica a presença de um conflito íntimo como causa do problema, parece considerar o desajustamento ao meio social apenas como a consequência de um desequilíbrio interno. Em seguida, porém, há uma indicação de que condições externas podiam provocar o surgimento de dificuldades, quando o autor afirma que, de acordo com a psicanálise, os primeiros anos de vida da criança tinham uma influência poderosa sobre a formação da sua personalidade.

A identificação de um aluno como sendo uma "criança-problema" era entendida uma questão delicada, já que os mesmos comportamentos podiam ser considerados normais em determinadas idades ou como indícios de um problema individual, a requerer tratamento, caso aparecessem em outra idade ou em um grau de intensidade incomum. Assim, mesmo as crianças normais corriam o risco de se tornarem "problemas", se viessem a sofrer algum tipo de influência ambiental desfavorável ao seu ajustamento. Por sua vez, a "criança-problema", desde que fosse submetida a medidas corretivas adequadas, poderia ser normalizada.

\section{Considerações Finais}

Para concluir o livro e resumir de maneira muito clara e sintética o conteúdo de sua proposta, Lourenço Filho representava em um diagrama todo o processo recomendado no livro, desde a aplicação dos testes até a investigação das dificuldades e a aplicação das medidas corretivas, num último esforço de inscrever e fixar as recomendações contidas no trabalho:

A visualização do esquema dá uma idéia de totalidade, que parece incluir todos os casos possíveis e sugere um percurso pré-estabelecido para todas as situações imagináveis. Parecia não haver caso que não pudesse ser encaminhado no sentido de levar uma criança normal a aprender a ler e a escrever. Em princípio, as crianças podiam ser duas coisas: maduras ou imaturas. Na situação mais complicada em que se revelassem imaturas, havia uma quantidade limitada de razões para essa dificuldade, cada uma das quais requerendo medidas específicas de correção. Mesmo em se tratando de "criança-problema", era possível, mediante um estudo clínico bem encaminhado, proceder ao reajustamento, de modo que, ao final do processo, percorrendo um caminho mais ou menos longo, todas as crianças "normais" se encontrariam na situação de usufruir do ensino regular, que por sua vez, seria adaptado às condições individuais.

Concluindo, a análise dos testes $A B C$ a partir da perspectiva da governamentalidade e da bio-política permite compreender como o invento de Lourenço Filho ajudou a tornar governáveis diversos aspectos das vidas dos alunos. Diante de um problema específico, o da dificuldade encontrada por grande parte dos alunos da primeira série para aprender a ler e a escrever, elaborou-se um instrumento que produzia informações sobre o nível de maturidade das crianças com vistas a classificá-las em turmas homogêneas. Mas a invenção dos testes $A B C$ permitia ainda empreender uma série de investigações acerca das relações entre o índice da maturidade e outras condições de vida das crianças, tais como: meio social de origem, organização familiar, alimentação e até seus conflitos íntimos. Isto porque, ao resolverem um problema de governo - o do elevado índice de reprovação nas primeiras séries - os testes evidenciavam outro, que era o de como tratar as crianças imaturas. $\mathrm{E}$ a solução desse novo problema também se iniciava pela aplicação dos testes. A observação atenta do examinador treinado já daria pistas da origem da dificuldade, embora fosse necessário recorrer a outras formas de diagnóstico que permitissem comprovar a primeira impressão. Detectada a causa, bastava dar início às "medidas de correção ou de compensação para as deficiências encontradas" para que logo a criança pudesse retomar o curso normal dos estudos. Finalmente, os testes ainda contribuíam para equacionar uma terceira questão de governo, a de se avaliar com justiça o desempenho dos professores, 
estabelecendo-se metas de alfabetização compatíveis com os níveis de maturidade de suas turmas.

\section{Referências}

Amorim, G. (1937). Classes selecionadas. Revista de Educação. São Paulo, v. I7-I8, mar/jun, I08-II2.

Campos, S. F. (1944). Reajustamento do escolar difícil - Relatório. Educação. São Paulo, v. 31, n. 42-43, 21 9-226.

Comissão de Estudos do S.I.A.E. (1939). Testes. Revista de Educação, 27, 28-63.

Foucault, M. (1999). História da Sexualidade I: a vontade de saber. (I $3^{\mathrm{a}}$ ed., M. T. C. Albuquerque \& J. A. G. Albuquerque, trad.). Rio de Janeiro: Graal. (Publicação original 1988).

Foucault, M. (1996). A Governamentalidade. Em M. Foucault (Org.) Microfísica do Poder ( $12^{\mathrm{a}}$. ed., R. Machado, trad.). Rio de Janeiro: Graal. (Publicação original 1979).
Lourenço Filho, M. B. (193I). Os Testes. Escola Nova, 2(3-4), 258.

Lourenço Filho, M. B. (1933). O problema da Maturidade para a Leitura e a Escrita. Revista de Educação, 3, 9I - 100.

Lourenço Filho, M. B. (1974). Testes ABC para verificação da maturidade necessária à aprendizagem da leitura e escrita. ( $12^{\mathrm{a}}$ ed.). São Paulo: Melhoramentos.

Penteado Junior, O. (1933). Os Testes A B C como meio de seleção de classes. Revista de Educação, I, I85-194.

Rose, N. (1999). Powers of Freedom: reframing political thought. Cambridge: Cambridge University Press.

Santos, A. (1945). A Seleção dos Escolares de Io. Grau pelos testes de maturidade. Revista de Educação, 34(48-49), 94- 102.

Vollet, G. B. (195I). A seleção de alunos e o rendimento escolar. Revista de Educação, 37(58), 53-56. 